\title{
A DIRECT APPROACH TO ARBITRAGE- FREE PRICING OF CREDIT DERIVATIVES
}

\author{
Sanjiv R. Das \\ Rangarajan K. Sundaram \\ Working Paper 6635 \\ http://www.nber.org/papers/w6635
NATIONAL BUREAU OF ECONOMIC RESEARCH
1050 Massachusetts Avenue
Cambridge, MA 02138
July 1998

Preliminary comments welcome. Do not cite without permission. Usage of the code in this paper is permitted only with full and proper attribution. Any opinions expressed are those of the author and not those of the National Bureau of Economic Research.

(C) 1998 by Sanjiv R. Das and Rangarajan K. Sundaram. All rights reserved. Short sections of text, not to exceed two paragraphs, may be quoted without explicit permission provided that full credit, including (C) notice, is given to the source. 
A Direct Approach to Arbitrage-Free Pricing of Credit Derivatives

Sanjiv R. Das and Rangarajan K. Sundaram

NBER Working Paper No. 6635

July 1998

\section{ABSTRACT}

This paper develops a model for the pricing of credit derivatives using observables. The model (i) is arbitrage-free, (ii) accommodates path-dependence, and (iii) handles a range of securities, even with American features. The computer implementation uses a recursive scheme that is convenient and seamlessly processes forward induction and backward recursion, needed to compute more complicated derivative securities.

Sanjiv R. Das

Harvard University

Graduate School of Business

Soldiers Field

Boston, MA 02163

and NBER
Rangarajan K. Sundaram

New York University

Stern School of Business

44 West 4th Street, MEC, 9th Floor

New York, NY 10012 


\section{INTRODUCTION}

Credit derivatives have attracted much attention in recent years, and are clearly a major asset class. A range of models has recently been developed to price these instruments. The goal of this paper is to present a modelling approach that is simple to implement, and is based on observables. The risk-neutral pricing approach is adopted, providing an arbitrage-free model for credit derivatives.

There is a vast literature on credit modelling, which began with the insights of Black and Scholes [3]. Fundamental valuation of the risky debt in a firm was thoroughly explored by Merton [21]. This class of models has now seen an extensive literature, as in Black and Cox [2], Bhattacharya and Mason [1], Kim, Ramaswamy and Sundaresan [16], Nielsen, Saa-Requejo and Santa-Clara [22], Shimko, Tejima and VanDeventer [24], Leland [18], Das [5], Huang [12], and Crosbie [4].

In a departure from the fundamental valuation of risky debt beginning with the designation of a firm value process, models nowadays simplify the mechanics by modelling risky debt directly. These models, popularly termed "reduced-form" models, have become widespread. There are three categories of these models (see Skora [25]): credit rating models, default models, and spread models. The credit rating models depict default through a gradual change in credit ratings over time, the mechanics being driven by a Markov transition matrix of rating changes. Examples of this literature are the papers of Lando [17], Das and Tufano [6] and Jarrow, Lando and Turnbull [14]. Default models define a stochastic process for default occurrence, such as in the models of Jarrow and Turnbull [15], Longstaff and Schwartz [19], Duffie and Singleton [11], Duffie and Huang [9] and Duffie, Schroder and Skiadas [10]. Finally, spread models directly posit a stochastic process for spreads, such as in Ramaswamy and Sundaresan [23], Madan and Unal [20], Longstaff and Schwartz [19], Duffee [8], and Das [7].

This paper offers a consolidated approach to reduced-form models, providing simple implementation mechanics. In contrast to term structure models for riskless debt, involving a parsimonious number of parameters, risky debt models require more information, all of which is not easily available. Moreover, the information is often not easily observable. The objective of this paper is to provide a model which may be implemented with as little information as possible, all of which is available.

The model begins with information on the term structure of riskless forward rates, and the term structure of credit spreads. The associated term structures of volatility of rates and spreads allows the development of an arbitrage-free bivariate tree using the Heath-Jarrow-Morton [13] technology. The values on this tree are then decomposed into default probabilities and recovery rates using a logit equation. Recursive equations provide additional information such as the cumulative default probabilities needed for pricing certain types of credit derivatives.

The computer model implements a multidimensional recursive equation system consistent with the absence of arbitrage. This paper provides a discrete-time model along the lines of Duffie, Schroder and Skiadas [10], and Duffie and Singleton [11]. While these papers allow for stochastic processes for default, recovery and discount factors, our paper models first the stochastic processes for riskless interest rates and spreads using the observable term structures of rates, spreads, and their attendant volatilities. Rather than positing the martingale measure, our implementation solves for the correct risk-neutral drifts of the stochastic processes to make credit-risky securities martingales after discounting. In discrete-time, this results in a bivariate lattice. We expand the information at each node on this bivariate lattice to determine default probabilities and recovery rates consistent with credit spreads. Since this information may result in path-dependent derivative security prices, such as occurs with the process for cumulative default probabilities, the recursive implementation of the paper offers a facile method by which to implement the model in an arbitrage-free way. 
Our model provides some distinct advantages. First, easy handling of American features in the pricing of credit derivatives is possible. Second, the path-dependence injected by default events is rendered computationally tractable. Third, the model uses less computer memory than standard implementations. Fourth, the model is consistent with the observed forward curves for interest rates and spreads.

Thus, the model prices credit risky securities in an arbitrage-free environment using readily available observable inputs. The following is the structure of the paper. Section 2 describes the model. Section 3 computes the risk-neutral process for interest rates, and Section 4 computes it for credit spreads. Section 5 contains the engineering details of the model. The conclusion is in Section 6.

\section{THE MODEL}

The model is developed in discrete time, since a computer implementation for options with American features and path-dependence is envisaged. We consider an economy on a finite time interval $\left[0, T^{*}\right]$. Time periods are denoted by $(t, T) \in\left[0, T^{*}\right]$. The discrete interval between dates is denoted $h$. A forward rate is defined as $f(t, T)$ which is the rate determined at time $t$ for a lending transaction over the interval $(T, T+h)$. Thus $f(t, T)$ denotes the one-period forward rate at time $T$ in the future as seen at time $t$. The process for forward rates in the economy is depicted by the discrete model below:

$$
f(t+h, T)=f(t, T)+\alpha(t, T, f(t, T)) h+\sigma(t, T, f(t, T)) X_{1} \sqrt{h}, \quad \forall T
$$

where $\alpha(t, T, f(t, T))$ is the drift which may be a function of current time, future forward rate time, and the level of the forward rates. The volatility coefficient $\sigma(t, T, f(t, T))$ has a similar interpretation. $X_{1}$ is a binomial random variable taking on a value of either +1 or -1 with equal probability. Of course, the analysis in this paper will accommodate any choice of random variable for $X_{1}$. We assume a fully observable vector of forward rates at current time $t$, i.e. $f(t, T)$ exists for all $T$. The "spot" rate of interest is defined to be $r(t)=f(t, t)$.

The pricing of bonds with default risk is driven off an existing term structure of credit spreads. We assume that a fully observable vector of forward spreads is available at time $t$. We denote this vector $s(t, T), \forall T$. The spreads also follow a process on the interval $\left[0, T^{*}\right]$ which is as follows:

$$
s(t+h, T)=s(t, T)+\beta(t, T, s(t, T)) h+\eta(t, T, s(t, T)) X_{2} \sqrt{h}, \quad \forall T
$$

where $\beta(t, T, f(t, T))$ is the drift and $\eta(t, T, f(t, T))$ is the volatility coefficient, which may be a function of current time, future forward spread time, and the level of the forward spreads. $X_{2}$ is a binomial random variable taking on a value of either +1 or -1 with equal probability. Both random variables $X_{1}$ and $X_{2}$ are governed by a probability measure denoted $P$.

The spreads represent the cost of default, and are functions of the probability of default, denoted $\lambda(t), \forall t$ and the recovery rate in the event of default, denoted $\phi(t), \forall t$. The recovery rate states the fraction of the current price of the risky bond that is recovered. We shall denote the price of the risky bond as $F(r, s, \tau)$ where $\tau$ is the remaining time to maturity of the bond. Likewise, we shall denote riskless bonds as $P(r, \tau),{ }^{1}$ since these securities are not functions of the credit spread. In the event of default at time $t$, the amount recovered is a proportion of current bond value, i.e. $\phi(t) F(r, s, \tau)$, where $\tau=T-t$, and $T$ is the bond's maturity date. This convention is referred to as "recovery of market value" (RMV), as detailed in Duffie and Singleton [11].

The model's objective is to develop a risk-neutral lattice for pricing risky debt. This is undertaken in two steps: (a) First, the riskless interest rates lattice is generated, by solving for the risk-neutral drifts so that all interest rate sensitive securities are martingales. This ensures the lattice if free from arbitrage. (b) Second, a lattice for credit spreads is superimposed on the first lattice, so as to implement the pricing of risky debt. Risk-neutral drifts are computed for the spread process so as to make the discounted prices of risky debt martingales.

\footnotetext{
${ }^{1}$ This is not to be confused with the probability measure $P$.
} 


\section{Risk-Neutral Process for Interest Rates}

We assume the existence of a risk-neutral measure under which the prices of securities are martingales. We shall denote this as measure $Q$ in order to distinguish it from the physical probability measure $P$. In order to derive the risk-neutral process, we proceed as in Heath, Jarrow and Morton [13].

We define a money market account to be the balance of an accumulation account accruing value from time $t=0$ continuously at rate $r(t)$ :

$$
B(t)=\exp \left[\sum_{i=0}^{\frac{t}{h}-1} r(i h) h\right] .
$$

The riskless bond is defined by the pricing equation

$$
P(t, T)=\exp \left[-\sum_{1=\frac{1}{h}}^{\frac{T}{h}-1} f(t, i h) h\right] .
$$

Under the $Q$ measure, all discounted asset prices will be martingales, and so

$$
\begin{aligned}
\frac{P(t, T)}{B(t)} & =E_{Q}\left(\frac{P(t+h, T)}{B(t+h)}\right) \\
& \Longrightarrow 1=E_{Q}\left(\frac{P(t+h, T)}{P(t, T)} \frac{B(t)}{B(t+h)}\right) .
\end{aligned}
$$

We can compute the components as follows:

$$
\begin{aligned}
\frac{P(t+h, T)}{P(t, T)} & =\exp \left[-\sum_{i=\frac{t}{h}+1}^{\frac{T}{T_{h}}-1} f(t+h, i h) h\right] \exp \left[\sum_{i=\frac{1}{h}}^{\frac{T}{h}-1} f(t, i h) h\right] \\
& =\exp \left[\left\{-\sum_{i=\frac{l}{h}+1}^{\frac{T}{h_{h}}-1}(f(t+h, i h)-f(t, i h)) h\right\}+f(t, t) h\right],
\end{aligned}
$$

and

$$
\begin{aligned}
\frac{B(t+h)}{B(t)} & =\exp \left[\sum_{i=0}^{\frac{1}{h}} r(i h) h\right] \exp \left[-\sum_{i=0}^{\frac{1}{h}-1} r(i h) h\right] \\
& =\exp [r(t) h] \\
& =\exp [f(t, t) h] .
\end{aligned}
$$

Therefore, from the martingale restriction we arrive at

$$
\begin{aligned}
E_{Q}\left[\exp \left\{-\sum_{i=\frac{1}{h}+1}^{\frac{T}{h}-1}[f(t+h, i h)-f(t, i h)] h\right\}\right. & =1 \\
E_{Q}\left[\exp \left\{-\sum_{i=\frac{1}{h}+1}^{\frac{T}{h}-1}\left[\alpha(i h) h+\sigma(i h) X_{1} \sqrt{h}\right] h\right\}\right. & =1 \\
E_{Q}\left[\exp \left\{-\sum_{i=\frac{t}{h}+1}^{\frac{T}{h}-1} \alpha(i h) h^{2}\right\} \exp \left\{-\sum_{i=\frac{1}{h}+1}^{\frac{T}{h}-1} \sigma(i h) X_{1} \sqrt{h} h\right\}\right. & =1
\end{aligned}
$$


which finally results in

$$
\sum_{i=\frac{l}{h}+1}^{\frac{T}{h}-1} \alpha(i h)=\frac{1}{h^{2}} \ln \left(E_{Q}\left[\exp \left\{-\sum_{i=\frac{l}{h}+1}^{\frac{T^{\prime}}{h}-1} \sigma(i h) X_{1} \sqrt{h} h\right\}\right]\right)
$$

which is a recursive equation defining the risk-neutral drift terms $\alpha(i h)$.

\section{Risk-Neutral Process for Default Spreads}

4.1. Martingale Dynamics. In this section, we derive the risk-neutral process for forward spreads [s $(t, T)]$ and "stitch" it on to the term structure of riskless interest rates derived in the previous section. This results in a bivariate system $[f(t, T), s(t, T)]$ off which risky debt may be priced.

The time $t$ price of a risky bond maturing at time $T$ is given by

$$
F(t, T)=\exp \left\{-\sum_{i=\frac{l}{h}}^{\frac{T}{h}-1}[f(t, i h)+s(t, i h)] h\right\}
$$

We define a "credit-adjusted" money market account $\left[B^{*}(t)\right]$ to be the balance of an accumulation account accruing value from time $t=0$ continuously at rate $r(t)+s(t, t)$ :

$$
B^{*}(t)=\exp \left\{\sum_{i=0}^{\frac{t}{h}-1}[f(i h, i h)+s(i h, i h)] h\right\} .
$$

Under the $Q$ measure, all discounted asset prices will be martingales, and so

$$
\begin{aligned}
\frac{F(t, T)}{B^{*}(t)} & =E_{Q}\left(\frac{F(t+h, T)}{B^{*}(t+h)}\right) \\
& \Longrightarrow 1=E_{Q}\left(\frac{F(t+h, T)}{F(t, T)} \frac{B^{*}(t)}{B^{*}(t+h)}\right)
\end{aligned}
$$

We can compute the components as follows:

$$
\begin{aligned}
\frac{F(t+h, T)}{F(t, T)}= & \exp \left[-\sum_{i=\frac{t}{h}+1}^{\frac{T}{h}-1}[f(t+h, i h)+s(t+h, i h)] h\right] \\
& \times \exp \left[\sum_{i=\frac{t}{h}}^{\frac{F}{h}-1}[f(t, i h)+s(t, i h)] h\right] \\
= & \exp \left[-\sum_{i=\frac{t}{h}+1}^{\frac{T}{h}-1}[f(t+h, i h)+s(t+h, i h)-f(t, i h)-s(t, i h)] h\right] \\
& \times \exp [f(t, t) h+s(t, t) h]
\end{aligned}
$$

and

$$
\frac{B^{*}(t+h)}{B^{*}(t)}=\exp [f(t, t) h+s(t, t) h]
$$


Therefore, from the martingale restriction we arrive at

$$
\begin{gathered}
E_{Q}\left[\exp \left\{-\sum_{i=\frac{t}{h}+1}^{\frac{T}{h}-1}[f(t+h, i h)+s(t+h, i h)-f(t, i h)-s(t, i h)] h\right\}\right]=1 \\
E_{Q}\left[\exp \left\{-\sum_{i=\frac{t}{h}+1}^{\frac{T}{h}-1}\left[\alpha(i h) h+\beta(i h) h+\sigma(i h) X_{1} \sqrt{h}+\eta(i h) X_{2} \sqrt{h}\right] h\right\}\right]=1
\end{gathered}
$$

which finally results in

$$
\sum_{i=\frac{i}{h}+1}^{\frac{T}{h}-1}[\alpha(i h)+\beta(i h)]=\frac{1}{h^{2}} \ln \left(E_{Q}\left[\exp \left\{-\sum_{i=\frac{i}{h}+1}^{\frac{T}{h}-1}\left[\sigma(i h) X_{1}+\eta(i h) X_{2}\right] h \sqrt{h}\right\}\right)\right)
$$

which is a recursive equation defining the risk-neutral drift terms $\alpha(i h)$ and $\beta(i h)$. Since $\alpha(i h)$ has already been computed, it is simple to solve recursively for $\beta(i h)$.

4.2. Correlation of forward interest rates and forward spreads. Empirically, it is known that spreads and interest rates are usually positively correlated. In addition, the degree of correlation tends to increase as the quality of risky debt declines. Imposing correlation on the random variables in the system above is fairly simple. We adopt a specific structure for random variables $\left[X_{1}, X_{2}\right]$. Under the $Q$ measure, we shall assume that the bivariate process takes values as follows: $\left[X_{1}, X_{2}\right]=\{(+1,+1),(+1,-1),(-1,+1),(-1,-1)\}$. Further, we set the probabilities equal to $\left\{\frac{1+\rho}{4}, \frac{1-\rho}{4}, \frac{1-\rho}{4}, \frac{1+\rho}{4}\right\}$. It can be readily checked that this yields a system in which the two processes are correlated with coefficient $\rho$. In general, since this set up applies at all times $t \in\left[0, T^{*}\right]$, the coefficient of correlation may be a general function, i.e. $\rho(r, s, t)$.

4.3. Components of the Forward Spread. Credit spreads may be delineated as functions of two influences: (a) the risk-neutral probability of default in time interval $h$ (denoted $\lambda()$.$h ), and (b) the risk-neutral$ recovery rate in the event of default (denoted $\phi($.$) ). The probability of default must decrease as the time$ interval $h$ shortens. Recovery may be expressed as a function of the face value of the instrument, its current traded value just before default, or as a percentage of another reference instrument. Duffie and Singleton [11] propose that recovery be a proportion of market value (denoted RMV for short). We shall see that the RMV convention is consistent with the bivariate model developed above.

Recall that the price of a one-period risky bond in the bivariate model is

$$
F(t, t+h)=\exp \{-[f(t, t)+s(t, t)] h\} .
$$

This must also equal a set of risky cashflows discounted at the riskless rate of interest

$$
F(t, t+h)=\exp \{-f(t, t) h\}[\lambda(t, t) h \phi(t, t)+1-\lambda(t, t) h]
$$

where $\lambda(t, t) h \phi(t, t)$ is the probability of default times the recovery amount, and $(1-\lambda(t, t) h) 1$ is the probability of no default times 1 , the market value of the zero-coupon bond at maturity. Since $\lambda$ is decreasing in $h$, as $h$ goes to zero, the term $\lambda(t, t) h \phi(t, t)+1-\lambda(t, t) h$ may be written as $e^{-\lambda(t, t) h[1-\phi(t, t)]}$ (per Duffie-Singleton, from the property that $e^{-x} \simeq 1-x$, for $x$ small). This results in the equation

$$
F(t, t+h)=\exp \{-f(t, t) h-\lambda(t, t) h[1-\phi(t, t)]\}
$$


This implies that $s(t, t)=\lambda(t, t)[1-\phi(t, t)]$. Therefore, in general

$$
\begin{aligned}
F(t, T)= & \exp \left\{-\sum_{i=\frac{t}{h}}^{\frac{T}{h}-1}[f(t, i h)+s(t, i h)] h\right\} \\
= & \exp \left\{-\sum_{i=\frac{t}{h}}^{\frac{T}{h}-1}[f(t, i h)+\lambda(t, i h)[1-\phi(t, i h)]] h\right\} \\
= & \exp \left\{-\sum_{i=\frac{t}{h}}^{\frac{T}{h}-2}[f(t, i h)+\lambda(t, i h)[1-\phi(t, i h)]] h\right\} \\
& \times \exp \left\{-\sum_{i=\frac{T}{h}-1}^{\frac{T}{h}-1}[f(t, i h)+\lambda(t, i h)[1-\phi(t, i h)]] h \times 1\right. \\
= & \exp \left\{-\sum_{i=\frac{t}{h}}^{\frac{T}{h}-2}[f(t, i h)+\lambda(t, i h)[1-\phi(t, i h)]] h\right\} F(T-h, T)
\end{aligned}
$$

The last line shows that if the recovery is written as recovery of market value, we obtain a recursive relation that allows us to directly price risky bonds directly off the forward curves for interest rates and spreads.

4.4. Decomposition of the Spread. The one-period forward spread $s(t, t ; \varpi)$ summarizes the market's expectation of future default probabilities and recovery rates over one period at time $t$ in the future. (Here, $\approx$ depicts the random outcome on the state-space). Without additional information, it is not possible to decompose the spread into these two fundamental components. We already have one equation for spread decomposition, i.e. $s(t, t, \varpi)=\lambda(., \varpi)[1-\phi(t, t, \varpi)]$. Any additional equation will allow us to solve for the two components $\lambda(., \varpi), \phi(t, t, \varpi)$. In keeping with the spirit of this paper, a readily observable means of identification is desirable.

One simple approach is to define $\lambda$ as a function of the level of the forward interest rates and spread curves, i.e. $\lambda(\mathbf{f}, \mathbf{s})$, where $\mathbf{f}, \mathbf{s}$ stand for the entire forward curves. Since $\lambda$ is a probability, to ensure that it resides on $[0,1]$ we choose a function that has a range in that interval. The logit equation $\lambda(r, s)=\frac{e^{x}}{e^{r}+1}, x=$ $a_{0}+\mathbf{b}^{\prime} \mathbf{f}+\mathbf{c}^{\prime} \mathbf{s} \in(-\infty,+\infty)$ is one simple choice of default probability function. Since $\lim _{x \uparrow \infty}\left(\frac{e^{x}}{e^{x}+1}\right)=1$ and $\lim _{x \downarrow-\infty}\left(\frac{e^{x}}{e^{x}+1}\right)=0$, this satisfies the range requirements. Essentially, we can find the function for $\lambda$ by means of a logit regression. Once this has been ascertained, for each outcome of $(f, s)$ we have a corresponding value of $\lambda$. Given the value for $\lambda$, the value for the recovery rate derives from $\phi(t, t)=1-s(t, t) / \lambda$. It is clear from this expression that for $\phi \in[0,1]$, we need to impose the condition that $\lambda \geq s$. This may be directly imposed in the logit regression or indirectly checked during computations of the model. The paper by Wilson [26] provides strong support for this sort of model. He finds that a logit regression fits default rates with adjusted $R^{2}$ values in the range of $80-90 \%$.

\section{The EngineERING IMPLEMEntation}

This discrete-time model may be easily implemented on a lattice. The model is bivariate, and the statespace described in section 4.2 is a simple implementation approach. This leads to a branching process with four branches emanating from each node. Once the risk-neutral drifts $\alpha(),. \beta($.$) have been computed,$ the values of the forward curves for interest rates and spreads under the martingale measure are available. Given the curves $[f(t, T), s(t, T)]$ we may also compute the one-period default probability $\lambda$ (using the logit equation) and the recovery rate $\phi$ at each node on the lattice. Therefore, at each node on the lattice we 
have information related to all three risks involved in the valuation of risky debt: interest rates, default probabilities and recovery rates. The use of the HJM model also ensures that we have the entire forward curve for riskless rates and spreads at each node. The lattice with its components appears as follows:

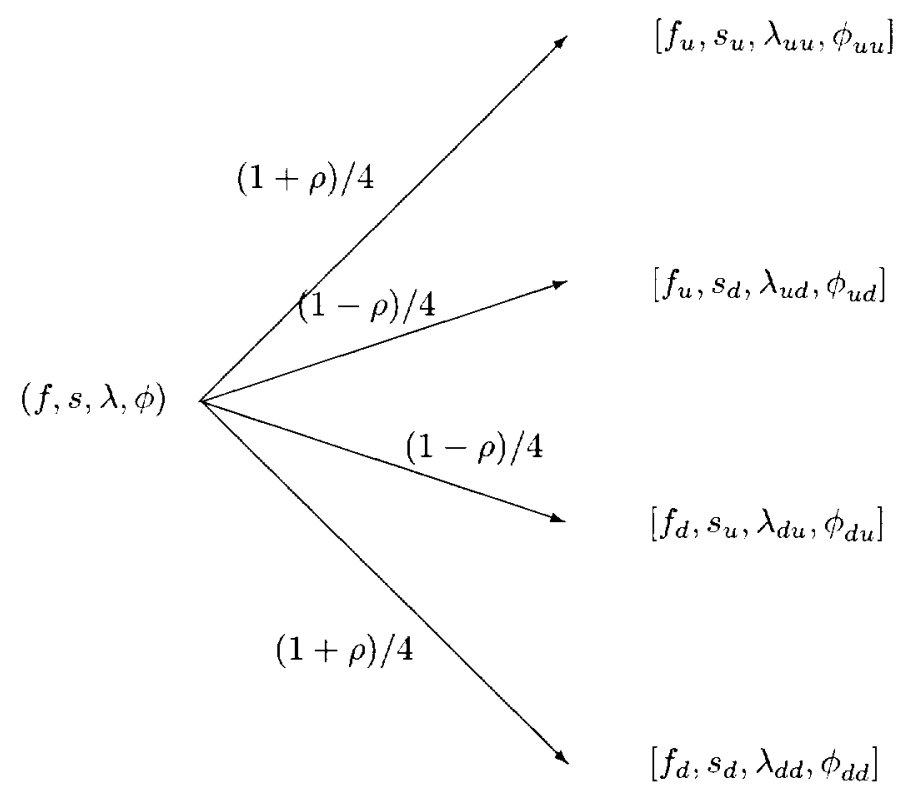

5.1. Lattice Enrichment. In addition, the computation of the following values makes for efficient implementation.

1. At each node, we compute state prices, which we denote $w(t, \varpi)$, for every random occurrence $(\varpi)$ at each time $t$. State prices may be computed recursively by means of the following equation:

$$
w(t+h, \varpi)=w(t) \exp [-r(t) h] \times \operatorname{prob}(\varpi), \quad w(0)=1 .
$$

Here, $\varpi$ represents the random choice of one of the four branches of the lattice at each node at time $t$. The advantage of computing state prices derives from the fact that it makes it easy to compute the price of a derivative claim by generating payoffs on the lattice and directly multiplying these by the state prices and aggregating the values.

2. Cumulative probabilities of default. We denote these values as $\Lambda(t)$. Since $\lambda(t)$ denotes the one-period forward probabilities of default, the following recursive equation describes the evolution of cumulative default probabilities.

$$
\Lambda(t+h, \varpi)=\Lambda(t)+[1-\Lambda(t)] \lambda(t, \varpi) h, \quad \Lambda(0)=0 .
$$

The interpretation of $\varpi$ is the same as that for state prices above. The recursive equation ensures that $\Lambda(t)$ and $\lambda(t)$ exist on the support $[0,1]$.

With the computation of these additional values, the lattice is enhanced to include cumulative default probabilities, and state prices. This provides all the necessary information for pricing a range of credit derivatives. The branching lattice now appears as follows: 


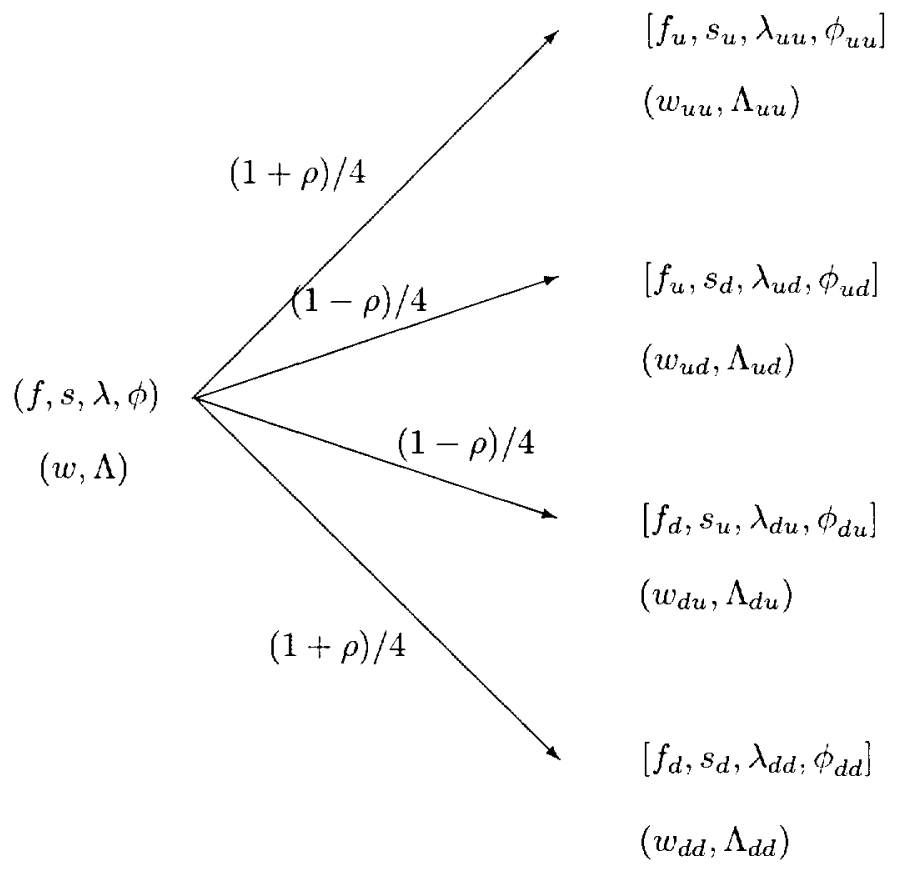

5.2. Lattice Computation via Recursion. Generating the lattice requires careful computation. A popular method is to use a recursive algorithm. A recursive algorithm is a function that calls itself repeatedly. Option pricing uses a recursion scheme quite naturally because on a lattice, the value at any node is a function of values at future nodes. Recursive algorithms provide two simple benefits: first, the program code is parsimonious, and second, the recombination of branches on the lattice is not an issue. The recursive algorithm simply follows each sample path to its conclusion. However, when a satisfactory recombination scheme is available, a recursive algorithm may be inefficient, because it misses the opportunity to optimize the lattice for speed. We describe the recursive algorithm in some detail.

Recursion is available since the lattice satisfies no-arbitrage conditions at each node. Hence, each subtree on the lattice may be treated separately. Knowledge of the values $[f, s, \lambda, \phi, w, \Lambda](t)$ allows direct extension into the next period's nodes $[f, s, \lambda, \phi, w, \Lambda](t+h, \varpi)$. Since the recursion allows path dependent values to be carried on the tree by forward induction, the value of any path-dependent derivative asset is easy to compute.

We price some popular credit derivatives as an illustration. The following examples of pseudo-code using Mathematica [27] demonstrates the programming technique.

5.2.1. Credit Spread Options. A credit spread option is a very simple credit derivative that is written on an underlying credit spread. A call option on a credit spread may be defined as a contract that pays off at some defined maturity if the spread is trading above a strike level (the exercise price). These options allow traders to speculate on a view regarding the quality of a bond. They also benefit option writers since credit spreads tend to be more volatile than interest rates, and hence the premiums on these options are rich. Furthermore. spread volatility declines rapidly towards bond maturity, making time decay an attractive feature for spread option writers. 
Pricing this derivative is simple. The payoffs are generated on the lattice at maturity by comparison of the spot spreads with the exercise level, and then discounted back appropriately. The code for this is provided below.

1 (* Program to generate the HJM Tree with default risk recursively *)\}

$2 \mathrm{CRD}\left[\mathrm{fO} \mathrm{O}_{-}, \mathrm{fsigO}, \mathrm{sO_{- }}, \mathrm{ssigO_{- } , \text { rho }}, \mathrm{h}_{-}\right.$, exprice $\left., \mathrm{a}_{-}, \mathrm{b}_{-}, \mathrm{c}_{-}\right]:=$Module [\}

$\{\mathrm{n}, \mathrm{puu}, \mathrm{pud}, \mathrm{pdu}, \mathrm{pdd}\}$,

$\mathrm{n}=$ Length $[\mathrm{fO}] ;\}$

puu $=(1+r h o) / 4 ;$ pdd=puu; pud= $(1-r h o) / 4$; pdu=pud; $\}$

CRVAL [level_, f , fsig_, $s_{-}$, ssig $_{-}$, cumdef $\left.]:=\right\}$

CRVAL [level,f,fsig, s, ssig, cumdef] = \}

Module $[\{i, m, j$, alpha, beta,fuu, fud, fdu, fdd, suu, sud, sdu, $\}$

sdd,fsigma, ssigma, pd, recov $\},\}$

If $[$ level $==n-1, \quad(*$ careful about $n$ or $n-1 *)\}$

result $=\operatorname{Max}[0, s[[1]]$-exprice $] * 100 ;\}$

] $\}$

If $[$ level<n-1,\}

$\mathrm{m}=$ Length $[\mathrm{f}]-1 ;\}$

fuu=Take $[f,-m]$; fud=fuu; fdu=fud; fdd=fdu; $\}$

suu=Take [s,-m] ; sud=suu; sdu=sud; sdd=sdu;\}

f sigma $=$ Take $[\mathrm{fsig},-\mathrm{m}] ;\}$

ssigma $=$ Take $[\mathrm{ssig},-\mathrm{m}] ;\}$

alpha=Table $[0,\{\mathrm{k}, \mathrm{m}\}] ;\}$

beta $=\mathrm{Table}[0,\{\mathrm{k}, \mathrm{m}\}] ;\}$

$\operatorname{For}[j=1, j<=m, j++$,

If $[j==1$,

alpha $[[j]]=\log [0.5 *(\operatorname{Exp}[-f \operatorname{sigma}[[j]] * h * \operatorname{Sqrt}[\mathrm{h}]]+\}$

$\left.\operatorname{Exp}[\mathrm{fsigma}[[j]] * \mathrm{~h} * \operatorname{Sqrt}[\mathrm{h}]])] / \mathrm{h}^{\wedge} 2 ;\right\}$

$\operatorname{beta}[[j]]=\log [$ puu*Exp $[(-f \operatorname{sigma}[[j]]-\operatorname{ssigma}[[j]]) * h * \operatorname{Sqrt}[h]]+\}$

$\operatorname{pud} * \operatorname{Exp}[(-\mathrm{f} \operatorname{sigma}[[j]]+\operatorname{ssigma}[[j]]) * h *$ Sqrt $[h]]+\}$

$\operatorname{pdu} * \operatorname{Exp}[(f \operatorname{sigma}[[j]]-\operatorname{ssigma}[[j]]) * h * \operatorname{Sqrt}[h]]+\}$

$\left.\operatorname{pdd} * \operatorname{Exp}[(\mathrm{fsigma}[[j]]+\operatorname{ssigma}[[j]]) * h * \operatorname{Sqrt}[\mathrm{h}]]] / \mathrm{h}^{\wedge} 2-\right\}$

alpha $[[j]] ;\}$

]$;\}$

If $[j>1$,

alpha $[[j]]=\log [0.5 *\}$

$(\operatorname{Exp}[-\operatorname{Sum}[\mathrm{fsigma}[[\mathrm{k}]],\{\mathrm{k}, \mathrm{j}\}] * \mathrm{~h} * \operatorname{Sqrt}[\mathrm{h}]]+\}$

$\left.\operatorname{Exp}[\operatorname{Sum}[f \operatorname{sigma}[[\mathrm{k}]],\{\mathrm{k}, \mathrm{j}\}] * \mathrm{~h} * \operatorname{Sqrt}[\mathrm{h}]])] / \mathrm{h}^{-} 2-\right\}$

Sum $[a l p h a[[k]],\{k, j-1\}] ;\}$

$\operatorname{beta}[[j]]=\log [\}$

$\operatorname{puu} * \operatorname{Exp}[\operatorname{Sum}[(-f \operatorname{sigma}[[j]]-\operatorname{ssigma}[[j]]) * h * \operatorname{Sqrt}[h],\{k, j\}]]+\}$

$\operatorname{pud} * \operatorname{Exp}[\operatorname{Sum}[(-\mathrm{fsigma}[[j]]+\operatorname{ssigma}[[j]]) * \mathrm{~h} * \operatorname{Sqrt}[\mathrm{h}],\{\mathrm{k}, \mathrm{j}\}]]+\}$

$\operatorname{pdu} * \operatorname{Exp}[\operatorname{Sum}[(\operatorname{figma}[[j]]-\operatorname{ssigma}[[j]]) * h * \operatorname{Sqrt}[\mathrm{h}],\{\mathrm{k}, j\}]]+\}$

$\left.\operatorname{pdd} * \operatorname{Exp}[\operatorname{Sum}[(f \operatorname{sigma}[[j]]+\operatorname{ssigma}[[j]]) * h * \operatorname{Sqrt}[h],\{k, j\}]]] / h^{-2}-\right\}$

Sum $[a l p h a[[k]],\{k, j\}]-S u m[\operatorname{beta}[[k]],\{k, j-1\}] ;\}$

]$;\}$

];\}

fuu $=$ fuutalpha*h+fsigma*Sqrt $[\mathrm{h}] ;\}$

fud $=$ fud + al pha*h+fsigma*Sqrt $[h] ;\}$

$f d u=f d u+a l p h a * h-f$ sigma*Sqrt $[h] ;\}$

$f d d=f d d+a l p h a * h-f$ sigma*Sqrt $[h] ;\}$ 
suu $=$ suu + beta $a$ h + ss igma $*$ Sqrt $[\mathrm{h}] ;\}$ sud=sud+beta*h-ssigma*Sqrt $[\mathrm{h}] ;\}$ sdu $=$ sdu+beta $* h+$ ssigma $*$ Sqrt $[h] ;\}$ sdd $=$ sdd+beta*h-ssigma*Sqrt $[\mathrm{h}] ;\}$ cumd $=(1-$ cumdef $) * \operatorname{Exp}[a+b * f[[1]]+c * s[[1]]] /(1+\operatorname{Exp}[a+b * f[[1]]+c * s[[1]]]) ;\}$

Two features of this code bear attention: (a) the use of recursive programming, and (b) the embedded boundary conditions. The boundary condition is provided in lines 10-11. The contract is assumed to be written on a notional value of $\$ 100$ for this implementation. Lines 6 thru 62 contain the recursive code function CRVAL. This code segment performs two distinct operations. First (in lines 21-43) it computes the risk-neutral drifts using the closed form expressions for $\alpha(),. \beta($.$) from the paper. Second, the function$ CRVAL calls itself recursively in lines 54-58. This recursive call exploits the feature that each subtree is arbitrage free in and of itself. Lines $44-52$ of the program set up the forward induction segment of the program, while the lines 54-58 implement backward recursion. In line 63, the initial call of the recursive function is made with the starting parameters of the model.

The recursive code has the advantage that the entire lattice need not reside in memory. If non-recursive methods are used, the need to store the lattice in memory increases the computing hardware requirement. The number of terminal nodes on the tree grows rapidly, and is $4^{n}$, where $n$ is the number of time steps. For example, even when $n=7,4^{7}=16384$, a considerable number of end-nodes.

5.2.2. Credit Default Swap. A credit default swap is another popular derivative security. In this swap, one party pays a steady stream of payments in exchange for one single compensatory payment only in the event of default of an underlying bond. The simplest form of this contract would be one where a single upfront payment is made to purchase default insurance. The payoff on default may be a predetermined lump-sum amount. It may also be defined as the loss in value from par value of the bond.

Valuing this option on the recursive lattice requires information on cumulative default probabilities along the sample path $[\Lambda(t)]$. This in turn requires the one-period probabilities of default $[\lambda(t)]$. As before, we define the probabilities using a logit function: $\lambda(t)=\frac{e^{n+b f t, t)+\operatorname{cs}(t, t)}}{1+e^{a+b f(t, t)+c \cdot s(t, t)}}$. The values of parameters $a, b, c$ are determined empirically. If the underlying bond has $n$ periods to maturity, then default is possible in any of the periods. To value the credit default swap, we generate default payoffs based on the recovery rates ( $\phi)$ at all points on the sample path. These payoffs are multiplied by the "first-passage" default probability, which is the probability of default conditional on no prior default. The first passage probability is given by the expression $[1-\Lambda(t)] \lambda(t)$. The payoff of the credit default swap is the loss on default, i.e. $[1-\phi(t)]$. The spreads are defined as $s(t, t)=\lambda(t)[1-\phi(t)]$. The expected cashflow to the derivative is given by the first-passage default probability times the loss on default, which is

$$
[1-\Lambda(t)] \lambda(t) \times[1-\phi(t)]=[1-\Lambda(t)] \lambda(t) \times \frac{s(t, t)}{\lambda(t)}=[1-\Lambda(t)] s(t, t)
$$


This is convenient since the recovery rate drops out of the expression (because $1-\phi(t)=s(t, t) / \lambda(t)$ ), and does not need to be computed in the program implementation. This expression is embedded in the program below in lines 12 and 55 of the code.

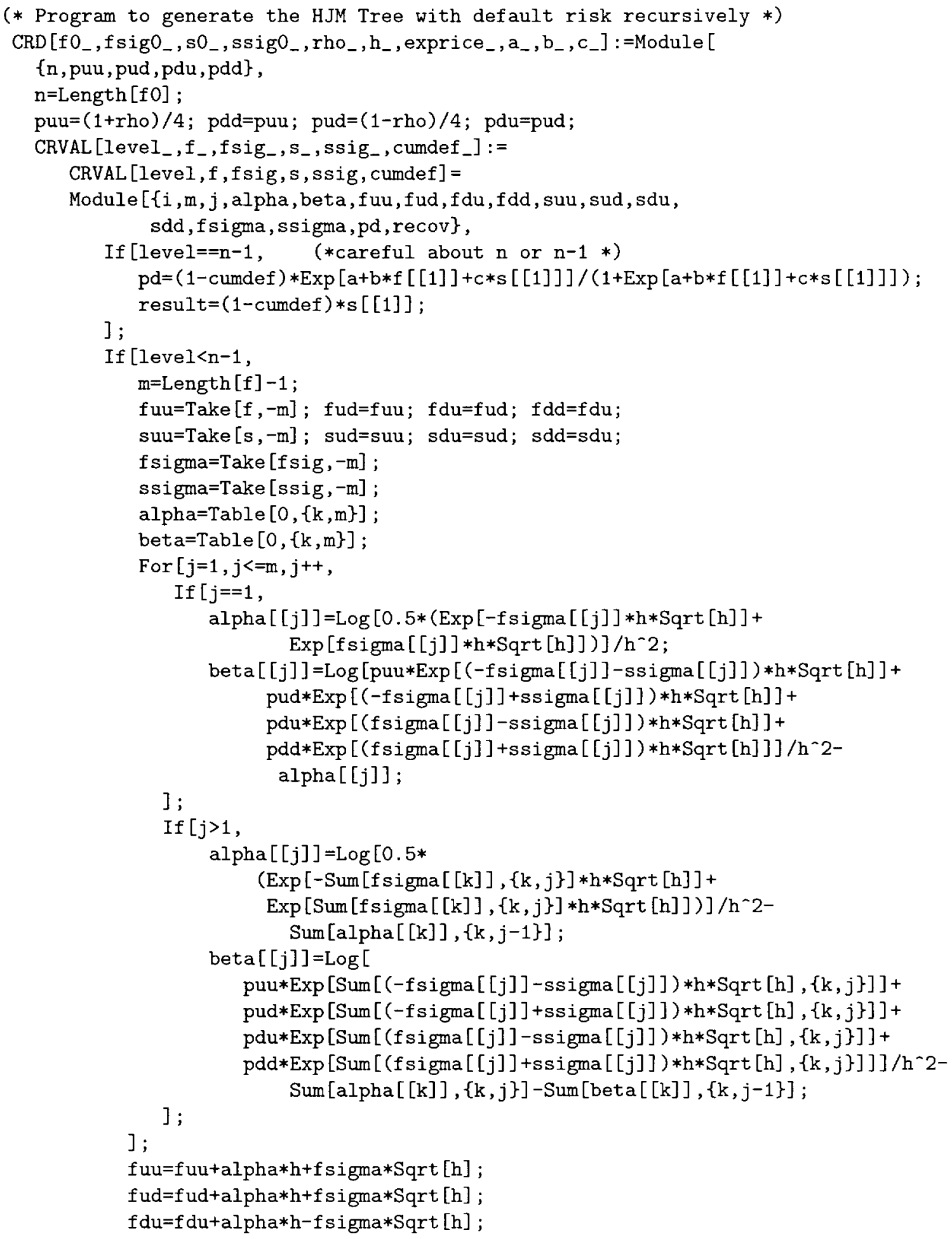




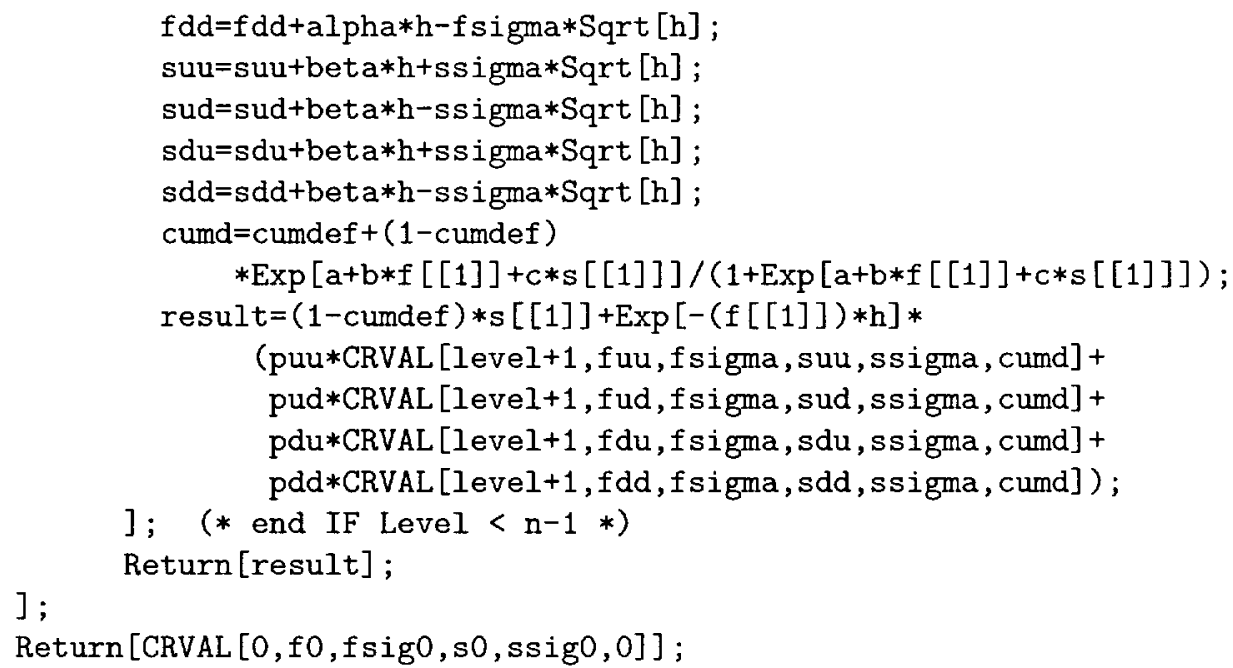

Some further aspects of the program code elicit interest. The code in lines 53-54 implements the recursive equation for forward induction of the cumulative default probabilities. The expression used is given before in equation (5.1) of the paper. Lines 55-59 implement backward recursion where the function CRVAL calls itself. Line 54 contains the expression for the one-period probability of default. In lines 56-59, the program passes on the current value of the cumulative default probability to the function next period, so that it can be carried ahead in time through forward induction. Since the cumulative probability of default has a trajectory that is path-dependent, the use of the recursive method offers efficient implementation.

5.2.3. Numerical Example. We implement a simple example to demonstrate the model and the two segments of code provided above. The implementation is undertaken using Mathematica [27]. The data used is as follows:

\begin{tabular}{ccccc}
\hline$T$ & $f(0, T)$ & $\sigma_{f}$ & $s(0, T)$ & $\sigma_{s}$ \\
\hline 0 & 0.06 & 0.015 & 0.010 & 0.005 \\
1 & 0.07 & 0.012 & 0.015 & 0.006 \\
2 & 0.08 & 0.011 & 0.020 & 0.007 \\
3 & 0.09 & 0.010 & 0.022 & 0.008 \\
\hline
\end{tabular}

\begin{tabular}{l|c}
\hline$\rho$ & 0.25 \\
$h$ & 0.50 \\
$a$ & -4 \\
$b$ & 10 \\
$c$ & 70 \\
\hline
\end{tabular}

These parameters were used on the code above. Results are:

- Credit spread option: The option was struck at a strike spread of 0.015 with a maturity of 3 periods. The notional value of the contract is $\$ 100$. The price of the option amounts to $\$ 0.75$, i.e. a premium of $0.75 \%$.

- Credit default swap: On a notional value of a dollar the default insurance premium computed is $\$ 0.027$, i.e. a premium of $2.7 \%$. The forward default probabilities were generated using the logit function $\lambda(t)=\frac{e^{a+b f(t, t)+r \cdot s(t, t)}}{1+e^{a+b f(t, t)+(\cdot s(t, t)}}=\frac{e^{-4+10 f(t, t)+70 *(t, t)}}{1+e^{-4+10 f(t, t)+70 *(t, t)}}$. A plot of this function is presented in Figure 1 .

Thus, we can achieve a range of values from a zero probability of default to almost an $80 \%$ chance of default. Since the recursive model results in parsimonious program code, the scheme in the paper should allow for boundary conditions and other forms of payoff functions which only require minor program modifications.

The program code may be extended to value several other instruments such as total return swaps, floating rate notes, auction-reset notes, spread-adjusted notes, etc., which are a small subset of the pantheon of credit 


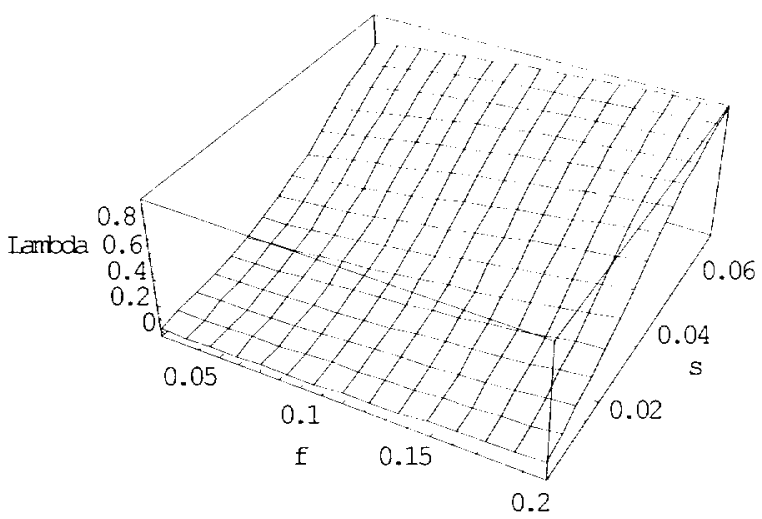

Figure 1

linked securities that have been created over the past few years. Additionally, the code may be translated into programming languages that compile and run faster, such as $\mathrm{C}++$.

\section{Concluding Comments}

This paper develops a model for the pricing of credit derivatives using observables. The model is (i) arbitrage-free, (ii) accommodates path-dependence, and (iii) handles a range of securities, even with American features. The computer implementation uses a recursive scheme that is convenient and seamlessly processes forward induction and backward recursion, needed to compute more complicated derivative securities.

The model may be enhanced in many ways. It is possible to improve the recursive implementation using improved computer science methods. That has not been the focus of this paper. Here, we attempt to simply develop the arbitrage-free framework underlying the computer implementation. Once the bivariate lattice in riskless rates and spreads has been developed, the spread itself may be decomposed into default probabilities and recovery rates in many ways other than the one suggested in the paper. For example, information in rating transition matrices may be employed instead of the logit regression. This paper leaves these rich avenues of research for later work.

\section{REFERENCES}

[1] BHATTACHARYA, S., and S. MASON (1981) "Risky Debt, Jump Processes and Safety Covenants," Journal of Financial Economics, v9(3), 281-307.

[2] BLACK, F., and J. COX (1976) "Valuing Corporate Securities: Some Effects of Bond Indenture Provisions," The Journal of Finance, v31(2), 361-367.

[3] BLACK, F., and M. SCHOLES (1973) "The Pricing of Options and Corporate Liabilities," Journal of Political Economy, v81, 637-654

[4] CROSBIE, P. (1997) "Modelling Default Risk," KMV Corporation.

[5] DAS, S.R. (1995) "Credit Risk Derivatives," Joumal of Derivatives, v2(3), 7-23.

[6] DAS, S.R., and P. TUFANO (1996) "Pricing Credit Sensitive Debt when Interest Rates, Credit Ratings and Credit Spreads are Stochastic," Journal of Financial Engineering, v5, 161-198.

[7] DAS, S.R. (1998) "Pricing Credit Derivatives," forthcoming, Handbook of Credit Derivatives

[8] DUFFEE, G. (1995) "Estimating the Price of Default Risk," working paper, Federal Reserve Buard of Governors, Washington.

(9] DUFFIE, D., and M. HUANG. (1996) "Swap Rates and Credit Quality," Journal of Finance, v51, 
[10] DUFFIE, D., M. SCHRODER, and C. SKIADAS. (1996) "Recursive Valuation of Defaultable Securities and the Timing of Resolution of Uncertainty," Annals of Applied Probability, v6, 1075-1090.

[11] DUFFIE, D., and K. SINGLETON (1996) "Modeling Term Structures of Defaultable Bunds," Working Paper, Stanford University.

[12] HUANG, J. (1996) "Option to Default and Optimal Debt Service," working paper, NYU.

[13] HEATH, D., R.A. JARROW, and A. MORTON (1990) "Bond Pricing and the Term Structure of Interest Rates: A Discrete Time Approximation," Journal of Financial and Quantitative Analysis, v25(4), 419-440.

[14] JARROW, R., D. LANDO, and S. TURNBULL. (1997) "A Markov Model for the Term Structure of Credit Spreads," Review of Financial Studies, v10, 481-523.

[15] JARROW, R., and S. TURNBULL. (1995) "Pricing Options on Financial Securities Subject to Default Risk," Journal of Finance, v50, 53-86.

[16] KIM, I.J., K. RAMASWAMY, and S. SUNDARESAN (1989) "The Valuation of Corporate Fixed Income Securities," working paper, Wharton School, University of Pennsylvania.

[17] LANDO, D. (1994) "Cox Processes and Credit-Risky Bonds," working paper, Cornell University.

[18] LELAND, H (1994) "Corporate Debt Value, Bond Covenants, and Optimal Capital Structure," Journal of Finance, v49, 1213-1252.

[19] LONGSTAFF, F., and E. SCHWARTZ. (1995) "A Simple Approach to Valuing Fixed and Floating Rate Debt," Journal of Finance, v50, 789-819.

[20] MADAN, D., and H. UNAL (1994) "Pricing the Risks of Default," working paper, University of Maryland.

[21] MERTON, R.C. (1974) "On the Pricing of Corporate Debt: The Risk Structure of Interest Rates," The Journal of Finance, v29, 449-470.

[22] NEILSEN, L., J. SAA-REQUEJO, and P. SANTA-CLARA (1993) "Default Risk and Interest Rate Risk: The Term Structure of Default Spreads," working paper, INSEAD, Fontainbleau, France.

[23] RAMASWAMY, K., and S. SUNDARESAN. (1986) "The Valuation of Floating Rate Instruments: Theory and Evidence," Journal of Financial Economics, v, 261-272.

[24] SHIMKO, D., N. TEJIMA, and D. VAN-DEVENTER (1993) "The Pricing of Risky Debt when Interest Rates are Stochastic," The Journal of Fixed-Income, v3, 58-65.

[25] SKORA, R. (1998) "Credit Modelling and Credit Derivatives: Rational Modelling," working paper, Skora and Co, Inc.

[26] WILSON, T. (1997) "Portfolio Credit Risk (1)," Risk, v10(9), September.

[27] WOLFRAM, S (1988) "Mathematica: A System for Doing Mathematics by Computer,".Addison-Wesley, California. 